\title{
A Meta-analysis of Language Abilities and Executive Function for Children with Cochlear Implants
}

\author{
Yoonhee Yang ${ }^{1}$, Dongsun Yim² \\ ${ }^{1}$ The Special Education Research Institute, Ewha Womans University, Seoul, Korea \\ ${ }^{2}$ Department of Communication Disorders, Ewha Womans University, Seoul, Korea
}

\author{
Received: January 27, 2021 \\ Revised: March 21, 2021 \\ Accepted: April 5, 2021 \\ Correspondence: \\ Yoonhee Yang, PhD \\ Department of Communication \\ Disorders, Ewha Womans \\ University, 52 Ewhayeodae-gil, \\ Seodamun-gu, Seoul 03760, Korea \\ Tel: $+82-2-3277-2120$ \\ Fax: +82-2-3277-2122 \\ E-mail: yunique0608@gmail.com
}

\begin{abstract}
The purpose of this study was to identify the differences in language ability and executive functions of children with cochlear implants $(\mathrm{Cl})$ and their peer normal hearing $(\mathrm{NH})$ children, and to find out whether the auditory history (duration of $\mathrm{Cl}$ use, age at implantation) of $\mathrm{Cl}$ group plays a role as a moderator in controlling the effect size of the differences of the $\mathrm{Cl}$ and $\mathrm{NH}$ groups. A total of 77 articles were searched, 11 studies which met the inclusive and exclusive criteria were selected from three electronic databases (Academic Search Complete, Psyclnfo, PubMed). As a result, significant differences were identified in language ability and the five executive function subtypes (working memory, inhibition, shifting, emotion control, and sustained sequential processing) between two groups. But, the hearing history of $\mathrm{Cl}$ group (duration of $\mathrm{Cl}$ use, age at implantation) did not appear as a significant moderator. In conclusion, $\mathrm{Cl}$ children's language ability and executive function should be precisely monitored and regularly evaluated. In addition, we discussed the possibility that some executive function abilities (plan/organize, attention, and visuo-spatial organization) will remain in $\mathrm{Cl}$ group. For the follow-up study, we need to identify various factors that support the $\mathrm{Cl}$ children.
\end{abstract}

Key Words: Meta-analysis, Language abilities, Executive function, Cochlear implants, Children.

\section{INTRODUCTION}

인공와우 이식(cochlear implants, CI)수술은 많은 청각 장애 아동들에게 청각의 일부 속성을 회복시켜주며, 이른 시기 에 받을 경우 특히 구어기술 발달에 도움을 준다(Geers et al., 2003; Geers \& Sedey, 2011; Niparko et al., 2010). 조기에 인공와우 이식수술을 받은 아동들을 대상으로 종단연구를 실 시한 결과, 학령전기 동안 극적인 구어 향상을 보여 이식 이전 의 언어능력 발달의 궤적을 상회하는 모습을 보였다(Niparko et al., 2010). 이처럼 초기에 인공와우 이식수술을 받은 상당수 의 아동들은 8 9세까지 언어능력이 평균 범위 내에 들거나 거 의 평균에 근접할 수 있다고 보고되기도 하지만(Geers et al., 2003), 실제 연구 결과를 보면 CI 아동들에게 말, 언어능력, 읽 기쓰기 발달에 상당한 개인차가 있어, 매우 다양한 결과들이 보 고된다(Davidson et al., 2011; Ganek et al., 2012; Pisoni et al., 2008). 즉, 인공와우 이식 이후 CI 아동들의 말-언어능력 점

(c) This is an Open Access article distributed under the terms of the Creative Commons Attribution Non-Commercial License (https://creativecommons.org/ licenses/by-nc/4.0) which permits unrestricted non-commercial use, distribution, and reproduction in any medium, provided the original work is properly cited.
수에서 상당한 가변성이 발견되며, 상당수의 청각장애 아동들이 조용한 환경에서 거의 정상적인 구어기능을 수행할 수 있는 반 면, 여전히 최적의 말-언어능력을 보여주지 않는 아동들도 존재 한다(Eisenberg, 2007; Ganek et al., 2012; Niparko et al., 2010; Semenov et al., 2012; Tobey et al., 2013).

청각적 자극은 패턴의 탐지, 연속된 자극의 기억, 주의력 유 지와 같은 순차적 처리능력을 발달시키는 데 매우 중요하다 (Conway et al., 2009). 그러나 CI 아동들은 생애 초기에 이미 청각자극의 부족을 경험하고, 인공와우 이식 이후에도 질적으 로 저하된 청각적 자극에 노출되기 때문에 이것이 언어능력뿐 만 아니라 신경인지능력에도 영향을 미칠 수 있다(Conway et al., 2009; Kral et al., 2016; Kronenberger \& Pisoni, 2018; Pisoni et al., 2008). 뇌는 신경처리와 외부자극 간 상호작용 을 기반으로 발달하는 역동적 자기조직(self-organizing) 시스 템이다(Fischer \& van Geert, 2014; Goldenberg \& Galván, 2015; van Geert, 2009). 신경인지능력의 발달은 감각 경험 및 관련 자극에 의존하는 뇌 시스템의 근본적 발달과 가족, 교육, 임상시스템 내의 학습경험 등을 반영한다. 소리 패턴에 대한 초 기 청각경험과 활동은 주의 유지하기(예: 배경소음보다는 대화 
상대자의 말소리에 초점 맞추기) 등 통제된 정보처리 활동에 참 여할 수 있는 기회를 제공하여 영역 일반적인(domain-general) 실행-조직-통합(executive-organizational-integrative, EOI) 처리의 발달을 촉진한다(Beer et al., 2014). 따라서, 인지조절처 리, 주의력 유지, 순차적 구성 및 일시적 정보에 대한 유창한 처 리에 대한 초기 경험은 필수적이다.

선행 연구에 따르면, EOI 처리가 청각, 말, 언어능력 상실 및 지연 기간에 영향을 받을 수 있으며, 이러한 기저의 어려움이 청각장애 및 $\mathrm{CI}$ 아동의 말, 언어능력 증진에 대해 추가적인 변 화의 원천을 설명할 수 있다고 보고하였다(Beer et al., 2014; Geers et al., 2003). 이처럼 초기 청각경험과 활동은 '실행기 능(executive function)'과 같은 신경인지 발달에 특히 중요한 것으로 나타난다(Conway \& Pisoni, 2008; Conway et al., 2009). 실행기능과 관련하여 다양한 이론과 모델이 제안되었지 만, 공통적으로는 실행기능에 대해 전두엽(prefrontal cortex) 및 관련 뇌 영역의 기능과 관련하여 계획적이고 목표지향적인 행 동을 수행하는 데에 필요한 능동적인 능력으로 정의하고 있다 (Barkley, 2012; Kronenberger \& Pisoni, 2020). 실행기능 (executive function)과 관련된 많은 연구 결과들이 보고되고 있음에도 불구하고 그 하위유형에 대해서는 일관된 설명을 기술 하는 데 제한이 많다. 실행기능은 개념의 형성, 통제된 주의력 등 다양하면서도 서로 관련된 일련의 능력들을 광범위하게 포함하 는 것으로 알려져 있으며, 적절한 주의력(attention), 억제조절 (inhibitory control), 비구어 및 구어 작업기억(nonverbal and verbal working memory), 감정조절(emotion regulation), 계획(planning), 문제해결(problem solving) 등 자기 규제 적인 처리능력 등을 포함한다(Beer et al., 2014; Greiner, 2010; Kronenberger et al., 2014b). 즉, 실행기능은 주요 자 극에 적절하고 통제된 주의를 기울이고, 요구되지 않는 반응 을 억제하며, 자발적인 행동으로 목표를 달성하기 위해 자신의 행동을 의도적으로 수정하는 데에 사용된다(Barkley, 2013; Kronenberger et al., 2014b; Yang \& Yim, 2018). 실행기능 은 생후 첫 해 동안 생겨나며, 초기 성인기까지도 지속적으로 발 달한다고 알려져 있다(Steinberg, 2010). 특히, 실행기능은 의식 적으로 사고와 행동을 통제해야 하는 상황에서 요구되며, 자동 적 또는 학습된 행동을 넘어서거나 정신적 자원을 요구할 때 더 욱 관련된다(Diamond, 2013).

학령전기 아동의 실행기능 발달을 이해하는 것은 특히 중요한 데, 학령전기 실행기능은 청소년기의 자기통제력 및 스트레스와 좌절에 대처하는 능력을 예측하며 성인기의 신체적 건강, 재정 적 안정, 범죄와도 관련이 있기 때문이다(Moffitt et al., 2011). 여러 종단 연구를 통해 억제조절 및 작업기억력이 초등 저학년 시기의 수학 및 언어능력(특히 읽기쓰기)을 안정적으로 예측함
을 밝히기도 하였다(Blair \& Razza, 2007; Bull et al., 2008; McClelland et al., 2007). 이처럼 실행기능의 발달은 전 생애 적으로 일상생활 전반에 필요한 기초 기술을 제공하지만, CI 아 동의 실행기능 발달은 또래 건청 아동에 비해 지속적으로 부족 한 것으로 나타난다(Kronenberger et al., 2014b). Beer et al.(2011)의 연구에서는 5 18세의 CI 아동 45명의 부모들이 자 신의 자녀가 작업기억, 억제조절, 행동규제와 관련하여 더 많은 문제를 보인다고 평가하였다. 특히 언어를 매개로 한 억제조절 및 작업기억에서 CI 아동들의 어려움이 두드러지게 나타나기도 하였다(Figueras et al., 2008; Surowiecki et al., 2002).

건청 아동과 비교하여 많은 $\mathrm{CI}$ 아동들이 보이는 이와 같은 실 행기능 상의 어려움은 말-언어능력과 관련되거나 예측해주는 요 인으로 나타나기도 한다(Harris et al., 2013; Kronenberger et al., 2013a; Pisoni et al., 2011). Surowiecki et al.(2002) 는 6 14세 CI 아동의 시각적 기억력이 광범위한 언어능력과 유 의한 관련을 보였다. Figueras et al.(2008)의 연구에서는 8 12세 의 CI 아동에게서 연령, 청력손실 기간 등을 통제한 후, 언어능 력과 실행기능(예: 계획, 작업기억, 충동억제 등) 간 유의한 정적 상관관계를 보고하였다. 이와 같이 선행 연구들을 통해 CI 아동 의 언어능력과 실행기능 간 밀접한 연관성이 입증되고 있다. 언 어능력과 실행기능은 특히 초기 아동기에 상호 양방향으로 관 련되는데, 실행기능의 주요 구성요소인 통제된 주의력, 작업기 억, 계획 등이 언어습득과 언어처리에 사용될 수 있기 때문이다 (Kronenberger \& Pisoni, 2018). CI 아동들의 구어 작업기 억은 말 지각(Cleary et al., 2000; Nittrouer et al., 2013), 어 휘(Cleary et al., 2000; Nittrouer et al., 2013; Wass et al., 2008), 어휘학습(Willstedt-Svensson et al., 2004) 등과 관련 이 있었다. CI 아동의 억제 및 통제된 주의력 또한 말-언어능력과 관련이 있었는데 특히 시간 요구가 있을 때 관련되었다(Horn et al., 2004; Kronenberger et al., 2014b). Pichora-Fuller et al.(2016)은 CI 아동들이 듣기와 구어처리를 위한 부가적인 노 력을 기울여야 한다고 했는데, 이는 인공와우 이식으로 인한 저 하된 코딩 자극이 언어관련 과제를 수행하는 동안 더 많이 실행 기능에 의존해야 하기 때문이라고 해석하였다. 그 결과, 또래 건 청 아동에 비해 CI 아동에게서 실행기능과 구어기술 간 연관성 이 더 강하게 나타날 수도 있다(Kronenberger et al., 2014b). 예를 들어, 작업기억 용량에 부담(load)이 증가하면, CI 아동의 실시간 언어처리는 저하되지만 또래 건청 아동에게 미치는 부 담은 상대적으로 $\mathrm{CI}$ 아동에 비해 적게 나타나며, 이는 작업기억 이 CI 아동들의 언어처리에 더 큰 역할을 할 수 있음을 의미한 다(Kronenberger et al., 2014b). 또 다른 선행 연구에 의하면, CI 이식 이후 약 1 년이 지난 후의 초기 어휘 점수는 11 년 후의 구 어 작업기억을 예측하였고, 반대로 구어 작업기억은 학령기 아 
동의 차후 어휘, 읽기 점수와 관련이 있었다(Kronenberger et al., 2013a; Pisoni et al., 2011).

위와 같은 내용을 토대로 더 나은 실행기능을 지닌 CI 아동 들이 언어습득 환경에서 더 효율적으로 정보를 처리할 수 있거 나, 또는 더 나은 언어능력을 지닌 CI 아동이 자신의 행동, 감 정, 사고를 더욱 효율적으로 조절하기 위해 언어를 사용할 수 있 다. 또한, CI 아동이 또래 건청 아동에 비해 상대적으로 부족하 게 나타나는 실행기능의 하위요소는 보다 제한적이고 구체적으 로(예: 작업기억) 나타날 수 있어 세부 영역별로 살펴보는 것은 더 정확한 정보를 얻을 수 있기에 중요하다. 한편, 초기 청감각 박 탈 기간이 길어질수록 구어에 대한 부정적 영향을 언급하거나 (Castellanos et al., 2015), 더 긴 CI 사용 기간이 실행기능과 유의한 관련이 있었던 선행 연구(Beer et al., 2014)에 따라 CI 아동의 청각이력(인공와우 착용 기간, 인공와우 이식 연령) 또한 언어능력 및 실행기능에 기여하는 주요 변수가 될 수 있으므로 이에 대해서도 확인해보고자 한다(Geers, 2006; Niparko et al., 2010).

따라서 본 연구의 세부적인 연구 질문은 다음과 같다. 첫째, 인공와우 이식(CI) 아동 및 건청(normal hearing, $\mathrm{NH}$ ) 아동의 언어능력(전반적 언어, 상호작용 기술, 어휘, 의미, 형태, 구문, 화 용 등)은 유의한 차이가 있는가? 둘째, $\mathrm{CI}$ 아동 및 $\mathrm{NH}$ 아동의 실 행기능은 하위유형에 따라 유의한 차이가 있는가? 셋째, CI 아 동 및 $\mathrm{NH}$ 아동의 언어능력 및 실행기능의 차이에 CI 아동의 청 각이력(인공와우 착용 기간, 인공와우 이식 연령)이 유의한 조절 변수(moderator)로 나타나는가?

\section{MATERIALS AND METHODS}

\section{문헌의 검색}

본 연구에서는 Academic Search Complete, PsycInfo, PubMed 등의 데이터베이스에서 2010년 1월 1일부터 2020년 12 월 31일 기간 동안의 문헌검색을 실시하였다. 문헌 수집에 사용된 구체적인 검색어는 'cochlear implant', 'executive function', 'language ability'를 사용하였으며, Academic Search Complete에서 25건, PsycInfo에서 20건, PubMed에 서 32건, 총 77 건의 연구가 검색되었다.

논문의 선정기준(ex. full text, peer reviewed journals, language) 및 제외기준을 통해 최종 11 편의 논문을 선정하였 다. 포함기준은 1) 전문(full text)을 제공하는 학술저널로, 2) 2010년 1월 1일부터 2020년 12월 31일 기간 내 최근 10년 간 출판된 것으로, 3) 언어는 '영어'로, 4) CI 아동 및 통제집단인 $\mathrm{NH}$ 아동을 대상으로 하며, 5) 실행기능 및 언어능력을 측정한 점수에 대해 평균과 표준편차가 명시된 논문을 포함하였다.
논문의 제외기준은 1) 학술논문이나 전문(full text)이 제공되 지 않은 논문, 2) 최근 10년 내 출판되지 않은 논문, 3) 언어가 '영 어'가 아닌 논문, 4) 대상자가 CI 아동 및 $\mathrm{NH}$ 아동이 포함되지 않은 논문, 5) 실행기능 및 언어능력에 대해 평균 및 표준편차를 제시하지 않은 논문으로, 위 조건을 충족시키지 못할 경우 분석 대상에서 제외하였다. 논문의 선정 과정은 Figure 1 과 같다.

\section{데이터 코딩 및 신뢰도 평가}

최종 선정된 총 11 개 논문 데이터의 코딩은 연구자, 게재연도, 연구 내 CI 아동의 청각이력(연령, 인공와우 사용 기간, 인공와우 이식 당시 연령), 하위 영역별 실행기능(예: 작업기억, 억제, 전환) 및 언어능력, 어휘의 평균과 표준편차, 각 집단의 표본 크기 등을 데이터로 입력하였다. 코딩 작업은 본 연구의 연구자 1 인과 박사 과정생 1 인에 의해 실시되었으며, 모두 1 급 언어재활사 국가자격 증을 소지하고 있다. 신뢰도 평가를 위해 전체 데이터에 대한 검 사-재검사 신뢰도를 측정한 결과, 1 차적인 일치율은 $84.6 \%$ 였으 며, 추후 일치하지 않는 데이터는 상호검토 및 재확인 후 수정하 여 최종적으로 $100 \%$ 로 나타났다.

\section{출판편의 검증}

출판편의(publication bias)란 유의미한 결과가 나타나지 않 은 개별 연구는 발표에서 제외되고 유의미하게 나타난 결과 위 주로 논문이 발표됨으로써 발생하는 왜곡 현상을 말한다. 출판 편의가 존재하는지 여부를 판단하기 위한 방법으로는 각 개별 연구의 평균효과크기를 중심으로 대칭의 형태를 이루고 있는지

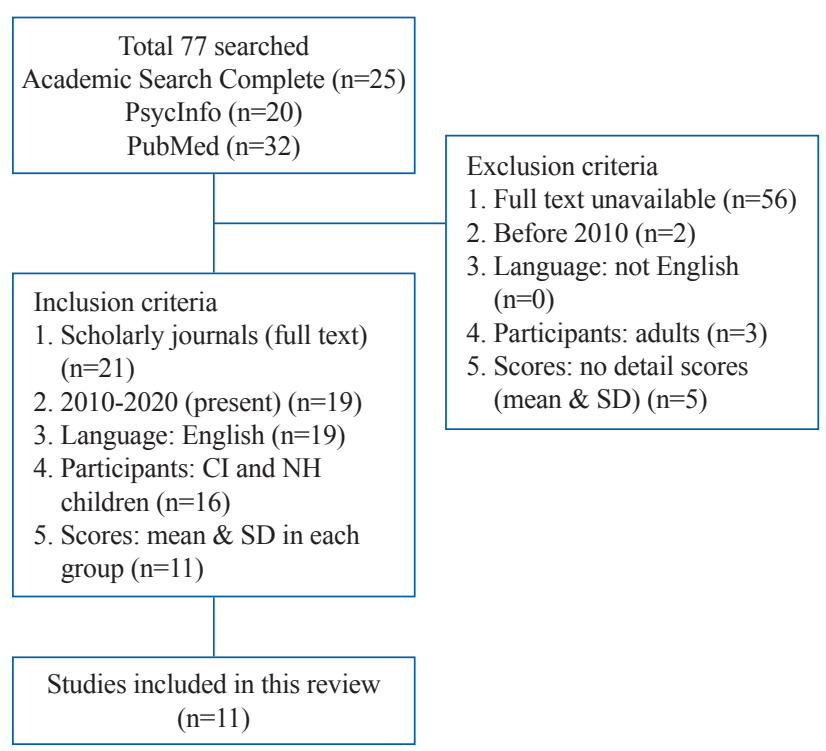

Figure 1. Flowchart of inclusion and exclusion criteria from database searching. SD: standard deviation, $\mathrm{Cl}$ : cochlear implants, $\mathrm{NH}$ : normal hearing. 
funnel plot을 통해 확인하는 방법이 있다. 출판편의 검증을 위 한 funnel plot은 Figure 2와 같다.

$x$ 축은 표준화 평균 차(standardized mean difference)인 관측된 효과크기를 나타내고, $\mathrm{y}$ 축은 그에 해당되는 추정된 표준 오차를 나타낸다. 가운데 수직 점선은 평균효과크기인 0.2616 을 나타내고 있으며, 좌우측 점선으로 표현한 경계선(사선)은 평 균효과크기를 중심으로 효과크기에 대한 95\% 신뢰구간을 나 타내고 있다. Rosental(1978)에 의하면, 효과크기-안정성 계수 (fail-safe N) 값이 클수록 효과크기 추정값을 더욱 신뢰할 수 있다고 하였다. 이에 따라 효과크기-안정성 계수를 산출한 결과, 그 값은 2,459 로 본 연구의 개별 연구의 수(k)인 11 편을 토대로 구한 값 $65=(5 \mathrm{k}+10)$ 보다 크다. 따라서 본 연구는 출판편의 영 향이 유의하게 작은 것으로 나타난다.

\section{메타분석}

본 연구의 메타분석을 위한 통계 프로그램은 R (ver. 4.0.3; R Foundation for Statistical Computing, Vienna, Austria) 을 사용하였으며 사용 패키지는 'meta (ver. 4.15-1)', 'metafor (ver. 2.4-0)'였다. CI 및 $\mathrm{NH}$ 아동집단의 언어능력, 실행기능의 차이에 대한 효과크기의 유의성을 검증하기 위하여 부분집단분 석을 실시하였으며, $\mathrm{CI}$ 및 $\mathrm{NH}$ 아동집단의 언어능력, 실행기능의 차이가 유의하다면, 그 결과에 CI 아동의 청각이력(인공와우 착 용 기간, 인공와우 이식 연령)이 유의한 조절변수(moderator)로 나타나는지 확인하기 위해 메타회귀분석을 실시하였다.

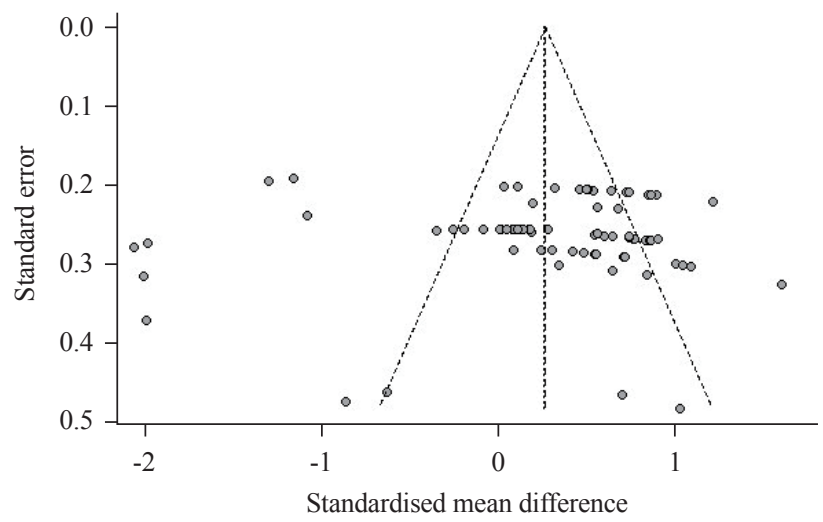

Figure 2. Funnel plot for verifying publication bias.

\section{RESULTS}

\section{질적 분석}

본 연구에서는 인공와우 이식 아동(CI)과 또래 건청 아동 $(\mathrm{NH})$ 을 대상으로 하는 논문들을 선정하여 메타분석을 실시하 였다. 대상자의 생활연령 범위는 4 15세(mean = 8.54)였으며, 인공와우 착용 기간은 1.13 12.36년(mean = 6.36), 인공와우 이식수술을 받은 연령은 18.79 50.58개월(mean = 25.62)이었 다. 이에 대한 세부적인 내용은 Table 1 에 제시하였다. 연구 대 상자의 수는 $\mathrm{CI}$ 아동 집단이 총 298명, $\mathrm{NH}$ 집단이 총 335 명이 었다.

분석 대상논문에서 사용된 언어평가도구는 The Preschool Language Scale-4 (Zimmerman et al., 2002), Peabody Picture Vocabulary Test (Dunn \& Dunn, 2007), Clinical Evaluation of Language Fundamentals (Semel et al., 2004)였으며, 실행기능평가도구는 The Behavior Rating Inventory of Executive Function (BRIEF; Gioia et al., 2000), The Learning, Executive, and Attention Functioning Scale (LEAF; Kronenberger, 2006)이 사용되 었다. 특히, BRIEF와 LEAF는 T점수로 환산한 점수를 사용하고 있어 점수가 높을수록 실행기능이 어려움을 의미한다. 본 연구 의 요약을 Appendix 1에 제시하였다.

\section{인공와우 이식(Cl) 아동 및 건청 $(\mathrm{NH})$ 아동의 언어능력의 차이}

$\mathrm{CI}$ 아동 및 $\mathrm{NH}$ 아동의 언어발달의 차이를 확인하기 위해 메 타분석을 실시하였다. 결과를 해석하기 위해 이질성 검정(test of heterogeneity)을 실시한 결과, Q-통계량의 값이 24.03 , 유의 확률이 0.00 으로 개별 연구들 간 이질성이 크게 나타났기에 고 정효과모형이 아닌 랜덤효과모형(random effects model)을 선 택하였다.

랜덤효과모형의 결과를 살펴보면, 교정된 표준화 평균 차 (Hedges' g)가 -1.48 (-1.80, -1.16) ( $p$ < 0.0001)로 나타났다. Hedges' g값은 표본이 작을 경우 효과크기를 과대 추정하지 않 도록 교정한 값이다. 이는 Cohen(1988)의 기준으로 볼 때 효과 크기가 크게(large) 나타난 것으로 해석된다. 즉, $\mathrm{CI}$ 아동과 $\mathrm{NH}$ 아동의 언어능력(전반적 언어, 상호작용 기술, 어휘, 의미, 형태,

Table 1. Participants' characteristics

\begin{tabular}{lcc}
\hline Variable & CI $(\mathrm{n}=298)$ & NH $(\mathrm{n}=335)$ \\
\hline Chronological age $(\mathrm{yr})$ & $8.54 \pm 3.29(4.12-15.43)$ & $8.50 \pm 3.41(3.99-16.01)$ \\
Duration of implant $(\mathrm{yr})$ & $6.36 \pm 2.96(1.13-12.36)$ & \\
Age at implantation $(\mathrm{mo})$ & $25.62 \pm 6.15(18.79-50.58)$ & \\
\hline
\end{tabular}

Values are presented as mean \pm standard deviation (range). CI: cochlear implants, $\mathrm{NH}$ : normal hearing 
구문, 화용 등)의 차이는 유의하게 큰 것으로 나타났다. 이에 대 한 결과를 Table 2, Appendix 2에 제시하였다.

\section{인공와우 이식 $(\mathrm{Cl})$ 아동 및 건청 $(\mathrm{NH})$ 아동의 실행기능 하위 영역 별 발달의 차이}

$\mathrm{CI}$ 아동 및 $\mathrm{NH}$ 아동의 실행기능 하위 영역별 발달의 차 이를 확인하기 위해 메타분석을 실시하였다. 먼저, 작업기억 (working memory) 결과를 해석하기 위해 이질성 검정(test of heterogeneity)을 실시한 결과, Q-통계량의 값이 8.75, 유의확 률이 0.36으로 0.05 보다 크므로 개별 연구들 간 차이는 동질적 이므로 고정효과모형(fixed effect model)을 선택하였다. 고정 효과모형의 결과를 살펴보면, 교정된 표준화 평균 차(Hedges' g) 가 $0.60(0.43,0.77)(p<0.0001)$ 로 나타났다. 즉, CI 아동과 $\mathrm{NH}$ 아동의 작업기억능력의 차이는 유의한 것으로 나타났다.

억제(inhibition) 결과를 해석하기 위해 이질성 검정(test of heterogeneity)을 실시한 결과, Q-통계량의 값이 7.07, 유의확 률이 0.31로 0.05 보다 크므로 개별 연구들 간 차이는 동질적이 므로 고정효과모형(fixed effect model)을 선택하였다. 고정효 과모형의 결과를 살펴보면, 교정된 표준화 평균 차(Hedges' $\mathrm{g}$ ) 가 $0.67(0.47,0.87)(p<0.0001)$ 로 나타났다. 즉, CI 아동과 $\mathrm{NH}$ 아동의 억제능력의 차이는 유의한 것으로 나타났다.

전환(shift) 결과를 해석하기 위해 이질성 검정(test of heterogeneity)을 실시한 결과, Q-통계량의 값이 4.67, 유의확 률이 0.32 로 0.05 보다 크므로 개별 연구들 간 차이는 동질적이
므로 고정효과모형(fixed effect model)을 선택하였다. 고정효 과모형의 결과를 살펴보면, 교정된 표준화 평균 차(Hedges' $\mathrm{g}$ ) 가 $0.45(0.24,0.66)(p<0.0001)$ 로 나타났다. 즉, $\mathrm{CI}$ 아동과 $\mathrm{NH}$ 아동의 억제능력의 차이는 유의한 것으로 나타났다.

계획/조직하기(plan/organize) 결과를 해석하기 위해 이질 성 검정(test of heterogeneity)을 실시한 결과, Q-통계량의 값 이 7.91, 유의확률이 0.09으로 0.05 보다 크므로 개별 연구들 간 차이는 동질적이므로 고정효과모형(fixed effect model)을 선 택하였다. 고정효과모형의 결과를 살펴보면, 교정된 표준화 평 균 차(Hedges' g)가 $2.62(-0.53,5.79)(p=0.10)$ 로 나타났다. 즉, $\mathrm{CI}$ 아동과 $\mathrm{NH}$ 아동의 계획/조직하기의 차이는 유의하지 않 았다.

감정조절(emotion control) 결과를 해석하기 위해 이질성 검 정(test of heterogeneity)을 실시한 결과, $\mathrm{Q}$-통계량의 값이 2.25 , 유의확률이 0.52 로 0.05 보다 크므로 개별 연구들 간 차이 는 동질적이므로 고정효과모형(fixed effect model)을 선택하 였다. 고정효과모형의 결과를 살펴보면, 교정된 표준화 평균 차 (Hedges' g)가 $4.70(2.25,7.16)$ ( $p=0.0002)$ 으로 나타났다. 즉, $\mathrm{CI}$ 아동과 $\mathrm{NH}$ 아동의 감정조절 차이는 유의하였다.

주의력(attention) 결과를 해석하기 위해 이질성 검정(test of heterogeneity)을 실시한 결과, Q-통계량의 값이 26.47 , 유의 확률이 0.00으로 0.05 보다 작으므로 개별 연구들 간 차이는 이질성이 크게 나타났기에 고정효과모형이 아닌 랜덤효과모형 (random effect model)을 선택하였다. 랜덤효과모형의 결과를

Table 2. Effect size of language ability and scores: $\mathrm{Cl}$ vs. $\mathrm{NH}$ groups

\begin{tabular}{|c|c|c|c|c|c|c|c|c|}
\hline \multirow{2}{*}{ Variable } & \multicolumn{4}{|c|}{ Effect size and 95\% confidence interval } & \multicolumn{4}{|c|}{ Test of heterogeneity } \\
\hline & Hedges' g & Lower limit & Upper limit & $p$-value & Q & $\mathrm{df}(\mathrm{Q})$ & $p$-value & $\mathrm{I}^{2}$ \\
\hline Language ability & -1.48 & -1.80 & -1.16 & $<0.0001^{* * *}$ & 24.03 & 8 & 0.00 & $66.7 \%$ \\
\hline
\end{tabular}

${ }^{* *} p<0.001$. CI: cochlear implants, NH: normal hearing

Table 3. Effect size of executive functions scores: $\mathrm{Cl}$ vs. $\mathrm{NH}$ groups

\begin{tabular}{|c|c|c|c|c|c|c|c|c|}
\hline \multirow{2}{*}{ Variable } & \multicolumn{4}{|c|}{ Effect size and 95\% confidence interval } & \multicolumn{4}{|c|}{ Test of heterogeneity } \\
\hline & Hedges' g & Lower limit & Upper limit & $p$-value & Q & $\mathrm{df}(\mathrm{Q})$ & $p$-value & $\mathrm{I}^{2}$ \\
\hline Working memory & 0.60 & 0.43 & 0.77 & $<0.0001^{\star * *}$ & 8.75 & 8 & 0.36 & $8.6 \%$ \\
\hline Inhibition & 0.67 & 0.47 & 0.87 & $<0.0001^{\star * *}$ & 7.07 & 6 & 0.31 & $15.1 \%$ \\
\hline Shift & 0.45 & 0.24 & 0.66 & $<0.0001^{\star * *}$ & 4.67 & 4 & 0.32 & $14.3 \%$ \\
\hline Plan/organize & 2.62 & -0.53 & 5.79 & 0.10 & 7.91 & 4 & 0.09 & $49.4 \%$ \\
\hline Emotion control & 4.70 & 2.25 & 7.16 & $0.0002^{* *}$ & 2.25 & 3 & 0.52 & $0.0 \%$ \\
\hline Attention & 6.49 & -2.77 & 15.76 & 0.16 & 26.47 & 2 & 0.00 & $92.4 \%$ \\
\hline Visual-spatial organization & 1.64 & -1.59 & 4.87 & 0.32 & 0.47 & 1 & 0.49 & $0.0 \%$ \\
\hline Sustained sequential processing & 9.50 & 5.26 & 13.75 & $<0.0001^{* * *}$ & 0.00 & 1 & 0.97 & $0.0 \%$ \\
\hline
\end{tabular}

${ }^{* * *} p<0.001 .{ }^{* *} p<0.01$. CI: cochlear implants, NH: normal hearing 
살펴보면, 교정화된 표준화 평균 차(Hedges' g)가 6.49 (-2.77, 15.76) ( $p=0.16$ )로 나타났다. Hedges' $\mathrm{g}$ 값은 표본이 작을 경우 효과크기를 과대 추정하지 않도록 교정한 값이다. 그 결과, CI 아 동과 $\mathrm{NH}$ 아동의 주의력 차이는 유의하지 않았다.

시공간적 조직(visual-spatial organization) 결과를 해석 하기 위해 이질성 검정(test of heterogeneity)을 실시한 결과, $\mathrm{Q}$-통계량의 값이 0.47 , 유의확률이 0.49 로 0.05 보다 크므로 개 별 연구들 간 차이는 동질적이므로 고정효과모형(fixed effect model)을 선택하였다. 고정효과모형의 결과를 살펴보면, 교정된 표준화 평균 차(Hedges' g)가 $1.64(-1.59,4.87)$ ( $p=0.32)$ 으로 나타났다. 즉, $\mathrm{CI}$ 아동과 $\mathrm{NH}$ 아동의 시공간적 조직의 차이는 유 의하지 않았다.

지속된 연속 처리(sustained sequential processing) 결과 를 해석하기 위해 이질성 검정(test of heterogeneity)을 실시한 결과, Q-통계량의 값이 0.00, 유의확률이 0.97로 0.05보다 크 므로 개별 연구들 간 차이는 동질적이므로 고정효과모형(fixed effect model)을 선택하였다. 고정효과모형의 결과를 살펴보 면, 교정된 표준화 평균 차(Hedges' g)가 9.50 (5.26, 13.75) $(p$ < 0.0001)으로 나타났다. 즉, $\mathrm{CI}$ 아동과 $\mathrm{NH}$ 아동의 시공 간적 조직의 차이는 유의하였다. 이에 대한 결과를 Table 3 , Appendix 2에 제시하였다.

\section{인공와우 이식 $(\mathrm{Cl})$ 아동 및 건청 $(\mathrm{NH})$ 아동의 언어능력 및 실행기 능 발달 차이에 대한 $\mathrm{Cl}$ 아동의 청각이력(인공와우 착용 기간, 인공 와우 이식 연령)의 기여 여부}

$\mathrm{CI}$ 아동 및 $\mathrm{NH}$ 아동의 언어능력, 총 여덟 가지 실행기능 하위 유형 중 다섯 개 영역(작업기억, 억제, 전환, 감정조절, 지속된 연 속 처리)의 차이를 확인하였으므로, CI 아동의 청각이력(인공와 우 착용 기간, 인공와우 이식 연령)이 두 집단의 언어능력 및 실 행기능 차이에 대한 평균효과크기를 조절하는 변수로 유의한 기 여를 하는 변수인지 알아보고자 조절효과분석을 실시하였다.

그 결과, CI 아동의 인공와우 착용 기간, 인공와우 이식 연령 을 공변인(covariate)으로 설정하였을 때, 두 집단의 언어능력, 실행기능 하위유형 5가지(작업기억, 억제, 전환, 감정조절, 지속 된 연속 처리)에서의 차이에는 유의한 기여를 하지 못하는 것으 로 나타났다 $(p>0.05)$. 즉, 본 연구에서는 CI 아동의 청각이력 은 두 집단의 언어능력 및 실행기능 발달 차이를 조절하는 조절 변수(moderator) 역할을 하지 못하는 것으로 나타났다.

\section{DISCUSSIONS}

본 연구에서는 인공와우 이식(CI) 아동 및 건청 $(\mathrm{NH})$ 아동의 언어능력 및 총 여덟 가지 실행기능 하위유형 중 다섯 개 영역(작
업기억, 억제, 전환, 감정조절, 지속된 연속 처리)에 따른 유의한 차이를 확인하였으며, $\mathrm{CI}$ 및 $\mathrm{NH}$ 아동 집단의 유의한 수행 차이 에 CI 아동의 청각이력(인공와우 착용 기간, 인공와우 이식 연령) 이 유의한 조절변수(moderator)로 나타나지는 못했음을 확인 하였다. 이에 대한 논의는 다음과 같다.

$\mathrm{CI}$ 아동들에게 말, 언어, 읽기쓰기 발달에는 상당한 개인차가 존재하는 것으로 보고되지만, 본 연구 결과를 통해 여전히 CI 아 동들에게 언어능력의 부족함은 상당히 명백하게 나타나는 것 으로 보인다. 구체적으로는 $\mathrm{CI}$ 아동들이 $\mathrm{NH}$ 아동에 비해 유의 하게 부족한 수용어휘, 수용언어능력을 보인 것으로 보고된다 (Conway et al., 2011; Holt et al., 2020). CI 아동들은 인공와 우 이식수술 이후 언어능력이 향상될 수 있으나, 이식 이후에도 질적으로 저하된 청각적 입력 또는 구어에 노출되기 때문에 이 것이 개념형성 및 언어 등 광범위한 측면에 영향을 미칠 수 있다 (Castellanos et al., 2015). 인공와우를 사용한 초기 경험은 언 어능력의 성장과 발전을 촉진하는 역할을 하므로 CI 아동 대부 분이 이식 후 음성 인식과 구어 기술의 현저한 발달을 보임에도 불구하고(Svirsky et al., 2000), 전반적 언어능력 또는 일부 언 어능력에서 또래 아이들보다 지속적으로 부족하게 나타난다는 선행 연구 결과와 일치한다(Geers et al., 2003).

이처럼 질적으로 저하된 초기 청각경험과 언어능력의 지연은 다른 신경인지능력에도 영향을 미칠 수 있는데, 청각 및 언어경 험과 기술은 자기조절 능력이 요구되는 상황에서 적절한 사고 와 행동을 지시하고 제어하는 데 사용될 수 있어 CI 아동의 언 어능력의 어려움이 관련된 다양한 기저능력과 연결고리를 가 질 수 있는 것이다. Figueras et al.(2008)은 8 12세 CI 아동 의 실행기능 지연에 대해 언어습득의 지연을 원인으로 추론하 기도 하였다. 몇몇 선행 연구에 따르면, $\mathrm{NH}$ 아동 집단과 비교 하여 더 많은 $\mathrm{CI}$ 아동들이 구어 단기기억 및 작업기억에서 평 균 이하의 성장을 보이고, 느린 작업기억능력의 성장은 추후 말언어능력을 예측하는 인자로 나타나기도 하였다(Harris et al., 2013; Kronenberger et al., 2013a; Pisoni et al., 2011). 또 한, CI 아동의 작업기억의 부족은 소음상황에서의 듣기, 구어로 문장 인식하기, 그림에 기초한 문장 구성하기 등 높은 인지 부하 (load)를 수반할 때 또래 $\mathrm{NH}$ 아동에 비해 더욱 문제가 될 수 있 다(Beer et al., 2011).

세부적으로 실행기능 하위 영역 중 작업기억, 억제, 전환, 감 정조절, 지속된 연속 처리에서 $\mathrm{CI}$ 및 $\mathrm{NH}$ 아동 간 차이가 유의하 였으나, 계획/조직하기, 주의력, 시공간적 조직과 같은 영역에서 는 두 집단 간 차이가 유의하지 않은 영역도 존재하였다. Beer et al.(2011)의 연구에서 CI 아동의 부모는 자녀가 작업기억, 억 제조절, 행동규제에 더 많은 문제를 보인다고 응답하였다. Beer et al.(2014)의 연구에서도 CI 아동은 $\mathrm{NH}$ 아동에 비해 작업기 
억, 억제 영역에서 유의하게 부족하였으나, 시각적 기억력(visual memory), 조직-통합(organization-integration), 계획/조직 하기(plan/organize)에서는 유의하게 부족하지 않아 본 연구와 일부 일치하였다. Beer et al.(2014)는 CI 아동이 NH 아동에 비 해 계획/조직하기(plan/organize)를 제외한 광범위한 실행기능 수행에서 임상적 범위가 더 넓게 나타났다고 보고하였다. 선행 연구에 따르면, 학령전기에 억제능력이 더 강한 아동이 그렇지 못한 아동에 비해 문해력, 어휘 증가가 더 높다고 보고되며, 통제 된 주의력, 작업기억, 계획은 언어습득과 처리에 사용되는 것으 로 보인다(Kronenberger \& Pisoni, 2018; Kronenberger \& Pisoni, 2020; McClelland et al., 2007). 이를 토대로 작업기 억을 비롯한 관련된 실행기능 하위유형에서의 개입은 유용할 수 있다(Kronenberger et al., 2013b).

또한 주목할 점은 본 연구에서 $\mathrm{CI}$ 아동의 지속된 연속 처리능 력이 $\mathrm{NH}$ 아동에 비해 크게 어려운 것으로 나타난 것으로 보아, $\mathrm{CI}$ 아동이 청각경험에 대한 접근 저하로 인해 광범위한 순차적 처리 결함을 가질 수 있음을 확인할 수 있다. 청각경험은 패턴의 감지, 연속된 자극의 기억, 주의력 유지와 같이 순차적 처리능력 발달에 매우 중요한 것으로 알려져 있어 $\mathrm{CI}$ 아동의 핵심적 어려 움으로 언급된다(Conway et al., 2009; Kronenberger et al., 2014b). 연속적 또는 순차적 처리의 결함은 순차적 자극에 대한 지속적인 주의력 및 작업기억과 같은 지속적이고 연속적인 처리 를 필요로 하는 전반적인 영역에 영향을 미칠 수 있다.

한편, 본 연구에서와 같이 $\mathrm{CI}$ 아동들은 또래 $\mathrm{NH}$ 아동과 비 교하여 시각적 조직 통합과 관련된 실행기능 영역에서는 지연 이 나타나지 않았다는 선행 연구들도 상당수 존재한다(Beer et al., 2014; Kronenberger et al., 2013b; Kronenberger et al., 2014b). 즉, CI 아동의 실행기능 지연은 조기에 시작되지 만, 실제로 일부 도메인(예: 시공간 조직)에서는 또래 $\mathrm{NH}$ 집단 과 유사한 발달이 나타나 그 능력이 잔존해 있거나 증진될 수 있음을 보여준다. 실제로 몇몇 실행기능 영역(예: 전환)은 또래 $\mathrm{NH}$ 아동과 비교하여 인공와우 이식 이후 발달이 가속화되었다 (Kronenberger \& Pisoni, 2020). 또는 실행기능의 하위유형에 따라 학령전기 내에서도 후기에 발달하는 영역은 그보다 더 어 린 나이에서는 집단 간 차이가 적게 나타날 가능성도 존재한다 (Kronenberger \& Pisoni, 2020).

이처럼 $\mathrm{CI}$ 아동 및 $\mathrm{NH}$ 아동의 언어능력과 실행기능 일부 유 형에서의 유의한 격차를 확인하였으며, 이러한 효과크기에 대 한 CI 아동의 청각이력의 영향력을 검토하고자 하였다. 이는 CI 아동의 언어능력 및 실행기능 조기 발달에 기여하는 기본 요소 를 더 잘 이해하기 위함이며, 실제로 조기의 인공와우 이식수술 의 구어기술 개선에 미치는 긍정적 효과를 보고한 연구(Geers et al., 2003; Niparko et al., 2010), 더 긴 인공와우 사용 기간
은 CI 아동의 계획/조직(plan/organize) 문제를 줄이는 데 관 련이 있었다고 보고한 연구(Beer et al., 2014)를 통해 인공와 우 이식 연령, 인공와우 사용 기간 등이 구어, 실행기능 등에 영 향력이 있는 요인일 수 있음을 확인하였다. 그러나 본 연구에서 는 $\mathrm{CI}$ 및 $\mathrm{NH}$ 아동 집단의 유의한 수행 차이에 CI 아동의 청각 이력(인공와우 착용 기간, 인공와우 이식 연령)이 유의한 조절 변수(moderator)로 나타나지는 못하였다. 이는 인공와우 이 식 이후에도 청각적 입력의 질 저하 및 구어 접근의 저하는 $\mathrm{NH}$ 아동에 비해 여전히 존재하며, 이러한 청각경험의 결핍이 언어 능력, 실행기능 등에 광범위한 영향을 미친다는 것을 시사한다. Kronenberger et al.(2013b)의 연구에서도 장기적 CI 사용자 들의 실행기능을 확인한 사례 연구를 통해 실행기능의 대부분은 청각이력과는 무관함을 밝혔다. 이는 CI 착용 기간이 장기화된 아동들이 CI 사용의 이점을 가지고 있음에도 불구하고 실행기 능의 몇 가지 핵심 영역에서 또래 $\mathrm{NH}$ 아동들의 능력에 도달하지 못할 수 있음을 시사한다.

본 연구의 제한점은 1) 분석 문헌의 총 자료 수가 제한적이며 국내 연구가 포함되어 있지 않다는 점, 2) 실행기능의 하위 영역 규정에 모호한 점, 3) 언어능력의 다양한 하위영역별 분석이 포 함되어 있지 않다는 점이다.

결론적으로, CI 아동의 언어능력과 더불어 실행기능을 정밀 하게 모니터링하고 정기적으로 평가해야 하며, 필요에 따라 적 절한 개입이 요구된다. 실행기능은 언어능력을 비롯한 광범위한 영역과 상호 관련되어 있으며, 실행기능의 발달을 강화할 수 있 는 개입과 경험은 $\mathrm{CI}$ 아동의 청각상실과 언어지연의 영향을 줄 일 수 있다(Kronenberger et al., 2013b). 본 연구에서는 CI 아 동의 언어능력, 실행기능의 격차를 조절하는 변수로 나타나지는 않았는데, 본 연구의 참여 아동의 CI 수술 연령이 평균적으로 약 25개월이나 그 범위가 18 50개월로 상당히 크며, 이미 인공와 우 이식 시기의 초기 발달 과정 중 언어능력 및 실행기능의 지연 과 장애위험이 높게 나타날 수 있다. 따라서, $\mathrm{CI}$ 아동의 언어능 력, 실행기능의 위험을 보호 또는 악화시킬 수 있는 영향력 있는 요인을 지속적으로 검증해 나가야 하며, 이는 $\mathrm{CI}$ 아동들의 결손 을 이해하고 적절한 중재를 제공하는 데 도움이 될 수 있을 것이 다. Holt et al.(2020)은 최근 CI 아동의 구어, 인지 영역과 더불 어 심리사회, 정서, 가족환경요인 등의 전반적인 관련성을 확인 하였는데, CI 아동을 둘러싼 지원적이고 상호작용이 풍부한 가 족환경이 언어능력, 심리사회적, 실행기능과 모두 유의한 관련이 있는 것으로 나타났다. 또한, CI 아동들에게 계획/조직하기, 주 의력, 시공간적 조직능력이 잔존할 가능성에 대해 논하였으므로 후속 연구에서는 이와 관련하여 $\mathrm{CI}$ 아동의 전반적인 발달을 지 원하고 보호하는 다양한 요인들을 확인해 나가는 작업이 지속되 어야 할 것으로 보인다. 
중심 단어 : 메타분석, 언어능력, 실행기능, 인공와우, 아동.

\section{Ethical Statement}

N/A

Acknowledgments

N/A

\section{Declaration of Conflicting Interests}

There are no conflict of interests.

\section{Funding}

This work was supported by the Ministry of Education of the Republic of Korea and the National Research Foundation of Korea (NRF-2020S1A5B5A16083276).

\section{Author Contributions}

Conceptualization: Yoonhee Yang, Dongsun Yim. Data curation: Yoonhee Yang. Funding acquisition: Yoonhee Yang. Investigation: Yoonhee Yang. Methodology: Yoonhee Yang. Project administration: Yoonhee Yang. Validation: Yoonhee Yang. Visualization: Yoonhee Yang. Writing_original draft: Yoonhee Yang, Dongsun Yim. Writing-review \& editing: Yoonhee Yang. Approval of final manuscript: Yoonhee Yang.

\section{ORCID iD}

Yoonhee Yang https://orcid.org/0000-0003-3240-5996

Dongsun Yim https://orcid.org/0000-0001-8254-9504

\section{REFERENCES}

AuBuchon, A. M., Pisoni, D. B., \& Kronenberger, W. G. (2015). Verbal processing speed and executive functioning in long-term cochlear implant users. Journal of Speech, Language, and Hearing Research, 58(1), 151-162.

Barkley, R. A. (2012). Executive Functions: What They Are, How They Work, and Why They Evolved. (1st ed.), (pp.1-244). New York, NY: Guilford Press.

Barkley, R. A. (2013). Distinguishing sluggish cognitive tempo from ADHD in children and adolescents: Executive functioning, impairment, and comorbidity. Journal of Clinical Child and Adolescent Psychology, 42(2), 161-173.

Beer, J., Kronenberger, W. G., Castellanos, I., Colson, B. G., Henning, S. C., \& Pisoni, D. B. (2014). Executive functioning skills in preschoolage children with cochlear implants. Journal of Speech, Language, and Hearing Research, 57(4), 1521-1534.

Beer, J., Kronenberger, W. G., \& Pisoni, D. B. (2011). Executive function in everyday life: Implications for young cochlear implant users. Cochlear Implants International, 12 Suppl 1(Suppl 1), S89-S91.

Blair, C. \& Razza, R. P. (2007). Relating effortful control, executive function, and false belief understanding to emerging math and literacy ability in kindergarten. Child Development, 78(2), 647-663.

Bull, R., Espy, K. A., \& Wiebe, S. A. (2008). Short-term memory, working memory, and executive functioning in preschoolers: Longitudinal predictors of mathematical achievement at age 7 years. Developmental Neuropsychology, 33(3), 205-228.

Castellanos, I., Kronenberger, W. G., Beer, J., Colson, B. G., Henning, S. C., Ditmars, A., et al. (2015). Concept formation skills in long-term cochlear implant users. Journal of Deaf Studies and Deaf Education, 20(1), 27-40.

Castellanos, I., Pisoni, D. B., Kronenberger, W. G., \& Beer, J. (2016). Early expressive language skills predict long-term neurocognitive outcomes in cochlear implant users: Evidence from the MacArthurBates communicative development inventories. American Journal of Speech-Language Pathology, 25(3), 381-392.

Cohen, J. (1988). Statistical Power Analysis for the Behavioral Sciences. (2nd ed.). Hillsdale, NJ: Erlbaum.

Conway, C. M. \& Pisoni, D. B. (2008). Neurocognitive basis of implicit learning of sequential structure and its relation to language processing. Annals of the New York Academy of Sciences, 1145, 113-131.

Conway, C. M., Pisoni, D. B., Anaya, E. M., Karpicke, J., \& Henning, S. C. (2011). Implicit sequence learning in deaf children with cochlear implants. Developmental Science, 14(1), 69-82.

Conway, C. M., Pisoni, D. B., \& Kronenberger, W. G. (2009). The importance of sound for cognitive sequencing abilities: The auditory scaffolding hypothesis. Current Directions in Psychological Science, 18(5), 275-279.

Cleary, M., Pisoni, D. B., \& Kirk, K. I. (2000). Working memory spans as predictors of spoken word recognition and receptive vocabulary in children with cochlear implants. The Volta Review, 102(4), 259280.

Davidson, L. S., Geers, A. E., Blamey, P. J., Tobey, E. A., \& Brenner, C. A. (2011). Factors contributing to speech perception scores in long-term pediatric cochlear implant users. Ear and Hearing, 32(1 Suppl), 19S-26S.

Diamond, A. (2013). Executive functions. Annual Review of Psychology, 64, 135-168.

Dunn, L. M. \& Dunn, D. M. (2007). Peabody Picture Vocabulary Test. (4th ed.). Minneapolis, MN: Pearson Assessments.

Eisenberg, L. S. (2007). Current state of knowledge: Speech recognition and production in children with hearing impairment. Ear and Hearing, 28(6), 766-772.

Figueras, B., Edwards, L., \& Langdon, D. (2008). Executive function and language in deaf children. Journal of Deaf Studies and Deaf Education, 13(3), 362-377.

Fischer, K. W. \& van Geert, P. (2014). Dynamic development of brain and behavior. In Molenaar, P. C. M., Lerner, R. M., \& Newell, K. M. Handbook of Developmental Systems Theory and Methodology (pp.287-315). New York, NY: The Guilford Press.

Ganek, H., McConkey Robbins, A., \& Niparko, J. K. (2012). Language outcomes after cochlear implantation. Otolaryngologic Clinics of North America, 45(1), 173-185.

Geers, A. E. (2006). Factors influencing spoken language outcomes in children following early cochlear implantation. Cochlear and Brainstem Implants, 64, 50-65.

Geers, A. E., Nicholas, J. G., \& Sedey, A. L. (2003). Language skills of 
children with early cochlear implantation. Ear and Hearing, 24(1), 46S-58S.

Geers, A. E. \& Sedey, A. L. (2011). Language and verbal reasoning skills in adolescents with 10 or more years of cochlear implant experience. Ear and Hearing, 32(1 Suppl), 39S-48S.

Gioia, G. A., Isquith, P. K., Guy, S. C., \& Kenworthy, L. (2000). Test review behavior rating inventory of executive function. Child Neuropsychology, 6(3), 235-238.

Goldenberg, D. \& Galván, A. (2015). The use of functional and effective connectivity techniques to understand the developing brain. Developmental Cognitive Neuroscience, 12, 155-164.

Greiner, L. A. (2010). Measures of executive function in children with cochlear implants (master's thesis). Iowa City, IA: University of Iowa.

Hall, M. L., Eigsti, I. M., Bortfeld, H., \& Lillo-Martin, D. (2018). Executive function in deaf children: Auditory access and language access. Journal of Speech, Language, and Hearing Research, 61(8), 1970-1988.

Harris, M. S., Kronenberger, W. G., Gao, S., Hoen, H. M., Miyamoto, R. T., \& Pisoni, D. B. (2013). Verbal short-term memory development and spoken language outcomes in deaf children with cochlear implants. Ear and Hearing, 34(2), 179-192.

Holt, R. F., Beer, J., Kronenberger, W. G., Pisoni, D. B., Lalonde, K., \& Mulinaro, L. (2020). Family environment in children with hearing aids and cochlear implants: Associations with spoken language, psychosocial functioning, and cognitive development. Ear and Hearing, 41(4), 762-774.

Horn, D. L., Davisa, R. A., Pisoni, D. B., \& Miyamoto, R. T. (2004). Visual attention, behavioral inhibition and speech/language outcomes in deaf children with cochlear implants. International Congress Series, 1273, 332-335.

Kral, A., Kronenberger, W. G., Pisoni, D. B., \& O’Donoghue, G. M. (2016). Neurocognitive factors in sensory restoration of early deafness: A connectome model. The Lancet Neurology, 15(6), 610621.

Kronenberger, W. G. (2006). Learning, executive and attention functioning (LEAF) scale. Clinical Child/Pediatric Psychology, Riley Child and Adolescent Psychiatry Clinic, William Kronenberger, Ph.D. Retrieved from https://drk.sitehost.iu.edu/LEAFinfo.html.

Kronenberger, W. G., Beer, J., Castellanos, I., Pisoni, D. B., \& Miyamoto, R. T. (2014a). Neurocognitive risk in children with cochlear implants. JAMA Otolaryngology - Head \& Neck Surgery, 140(7), 608-615.

Kronenberger, W. G., Colson, B. G., Henning, S. C., \& Pisoni, D. B. (2014b). Executive functioning and speech-language skills following long-term use of cochlear implants. Journal of Deaf Studies and DeafEducation, 19(4), 456-470.

Kronenberger, W. G. \& Pisoni, D. B. (2018). Neurocognitive functioning in deaf children with cochlear implants. In Knoors, H. \& Marschark, M. Evidence-Based Practice in Deaf Education (pp.363396). New York, NY: Oxford University Press.

Kronenberger, W. G. \& Pisoni, D. B. (2020). Why are children with cochlear implants at risk for executive functioning delays? In Knoors, H. \& Marschark, M. The Oxford Handbook of Deaf Studies in Learning and Cognition (pp.1-480). New York, NY: Oxford University Press.

Kronenberger, W. G., Pisoni, D. B., Harris, M. S., Hoen, H. M., Xu, H., \& Miyamoto, R. T. (2013a). Profiles of verbal working memory growth predict speech and language development in children with cochlear implants. Journal of Speech, Language, and Hearing Research, 56(3), 805-825.

Kronenberger, W. G., Pisoni, D. B., Henning, S. C., \& Colson, B. G. (2013b). Executive functioning skills in long-term users of cochlear implants: A case control study. Journal of Pediatric Psychology, 38(8), 902-914.

Liu, M., Wu, L., Wu, W., Li, G., Cai, T., \& Liu, J. (2018). The relationships among verbal ability, executive function, and theory of mind in young children with cochlear implants. International Journal of Audiology, 57(12), 881-888.

McClelland, M. M., Cameron, C. E., Connor, C. M., Farris, C. L., Jewkes, A. M., \& Morrison, F. J. (2007). Links between behavioral regulation and preschoolers' literacy, vocabulary, and math skills. Developmental Psychology, 43(4), 947-959.

Moffitt, T. E., Arseneault, L., Belsky, D., Dickson, N., Hancox, R. J., Harrington, H., et al. (2011). A gradient of childhood self-control predicts health, wealth, and public safety. Proceedings of the national academy of sciences of the United States of America, 108(7), 2693-2698.

Niparko, J. K., Tobey, E. A., Thal, D. J., Eisenberg, L. S., Wang, N. Y., Quittner, A. L., et al. (2010). Spoken language development in children following cochlear implantation. JAMA, 303(15), 14981506.

Nittrouer, S., Caldwell-Tarr, A., \& Lowenstein, J. H. (2013). Working memory in children with cochlear implants: Problems are in storage, not processing. International Journal of Pediatric Otorhinolaryngology, 77(11), 1886-1898.

Pichora-Fuller, M. K., Kramer, S. E., Eckert, M. A., Edwards, B., Hornsby, B. W., Humes, L. E., et al. (2016). Hearing impairment and cognitive energy: The framework for understanding effortful listening (FUEL). Ear and Hearing, 37 Suppl 1, 5S-27S.

Pisoni, D. B., Conway, C. M., Kronenberger, W. G., Horn, D. L., Karpicke, J., \& Henning, S. C. (2008). Efficacy and effectiveness of cochlear implants in deaf children. In Marschark, M. \& Hauser, P. C. Deaf Cognition: Foundations and Outcomes (pp.52-101). New York, NY: Oxford University Press.

Pisoni, D. B., Kronenberger, W., Roman, A., \& Geers, A. (2011). Measures in digit span and verbal rehearsal speed in deaf children following more than 10 years of cochlear implant use. Ear and Hearing, 32(1), 60s-74s.

Rosenthal, R. (1978). Combining results of independent studies. Psychological Bulletin, 85, 185-193.

Semel, E., Wiig, E. H., \& Secord, W. A. (2004). Clinical Evaluation of Language Fundamentals-Preschool. (2nd ed.). San Antonio, TX: The Psychological Corporation.

Semenov, Y. R., Martinez-Monedero, R., \& Niparko, J. K. (2012). Cochlear implants: Clinical and societal outcomes. Otolaryngologic Clinics of North America, 45(5), 959-981.

Steinberg, L. (2010). A behavioral scientist looks at the science of adolescent brain development. Brain and Cognition, 72(1), 160-164.

Surowiecki, V. N., Sarant, J., Maruff, P., Blamey, P. J., Busby, P. A., \& Clark, G. M. (2002). Cognitive processing in children using cochlear implants: The relationship between visual memory, attention, and executive functions and developing language skills. The Annals of Otology, Rhinology \& Laryngology, 111(5_suppl), 119126.

Svirsky, M. A., Robbins, A. M., Kirk, K. I., Pisoni, D. B., \& Miyamoto, R. T. (2000). Language development in profoundly deaf children with cochlear implants. Psychological Science, 11(2), 153-158. 
Tobey, E. A., Thal, D., Niparko, J. K., Eisenberg, L. S., Quittner, A. L., Wang, N. Y., et al. (2013). Influence of implantation age on schoolage language performance in pediatric cochlear implant users. International Journal of Audiology, 52(4), 219-229.

van Geert, P. (2009). Nonlinear complex dynamical systems in developmental psychology. In Guastello, S. J., Koopmans, M., \& Pincus D. Chaos and Complexity in Psychology: The Theory of Nonlinear Dynamical Systems (pp.242-281). Cambridge: Cambridge University Press.

Wass, M., Ibertsson, T., Lyxell, B., Sahlén, B., Hällgren, M., Larsby, B., et al. (2008). Cognitive and linguistic skills in Swedish children with cochlear implants - measures of accuracy and latency as indicators of development. Scandinavian Journal of Psychology, 49(6), 559-576. Willstedt-Svensson, U., Löfqvist, A., Almqvist, B., \& Sahlén, B. (2004). Is age at implant the only factor that counts? The influence of working memory on lexical and grammatical development in children with cochlear implants. International Journal of Audiology, 43(9), 506515.

Yang, Y. \& Yim, D. (2018). The role of executive function for vocabulary acquisition and word learning in preschool-age children with and without vocabulary delay. Communication Sciences and Disorders, 23(1), 43-59.

Zimmerman, I. L., Steiner, V. G., \& Pond, R. E. (2002). Preschool Language Scale. (4th ed.). San Antonio, TX:Psychological Corporation. 


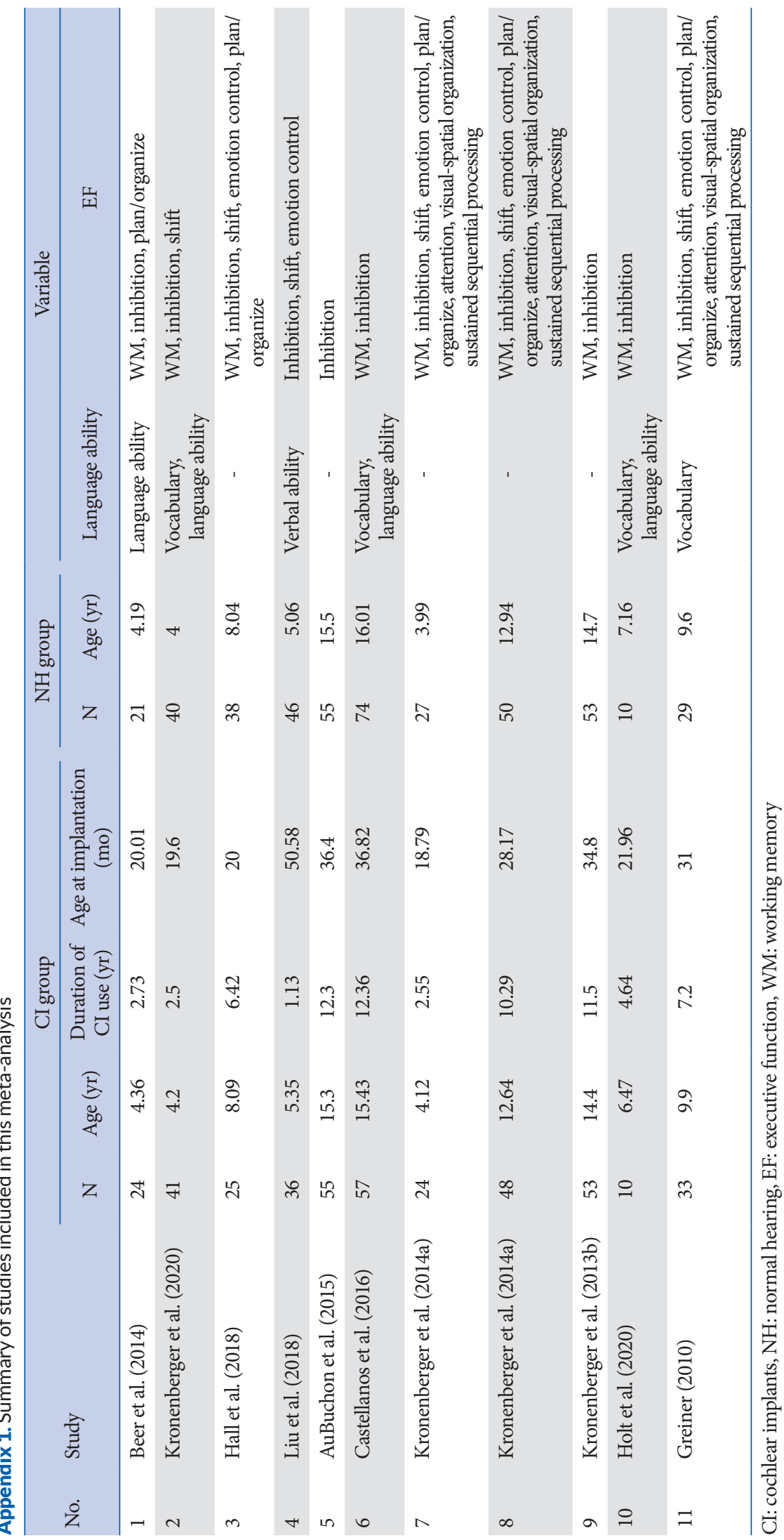


Appendix 2. Forest plot of meta-analysis

Language ability

\begin{tabular}{lccc} 
& \multicolumn{3}{c}{ Experimental } \\
Sutdy & Total & Mean & SD \\
1 & 24 & 78 & 24 \\
2 & 41 & 84 & 21 \\
3 & 41 & 81 & 24 \\
4 & 36 & 10 & \\
5 & 57 & 91 & 20 \\
6 & 57 & 90 & 24 \\
7 & 10 & 63 & 24 \\
8 & 10 & 78 & 13 \\
9 & 33 & 78 & 19
\end{tabular}

Random effects model 309

Heterogeneity: $I^{2}=67 \%, t^{2}=0.1514, p<0.01$
Control Standardised mean

Total Mean SD

difference

SMD

$95 \% \mathrm{CI}$

Weight

$\begin{array}{rrr}21 & 118 & 12 \\ 40 & 118 & 1 \\ 40 & 119 & 12 \\ 46 & 13 & \\ 74 & 111 & 15 \\ 74 & 113 & \\ 10 & 118 & 8 \\ 10 & 122 & 9 \\ 29 & 111 & 13\end{array}$

344

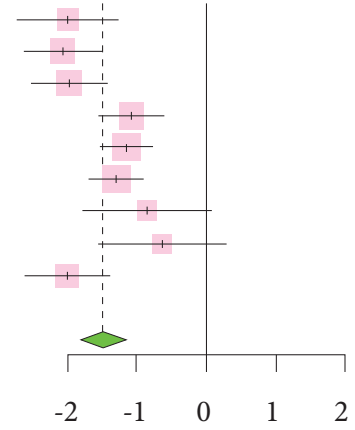

$-1.99 \quad[-2.72 ;-1.27] \quad 9.3 \%$

$-2.06 \quad[-2.61 ;-1.52] \quad 11.8 \%$

$-1.98 \quad[-2.52 ;-1.45] \quad 11.9 \%$

$-1.08 \quad[-1.55 ;-0.61] \quad 12.9 \%$

$-1.16 \quad[-1.53 ;-0.79] \quad 14.4 \%$

$-1.30 \quad[-1.68 ;-0.92] \quad 14.3 \%$

$-0.86 \quad[-1.79 ; 0.06] \quad 7.2 \%$

$-0.63 \quad[-1.53 ; 0.28] \quad 7.4 \%$

$-2.01 \quad[-2.63 ;-1.39] \quad 10.8 \%$

$-1.48 \quad[-1.80 ;-1.16] \quad 100.0 \%$

Working memory

\begin{tabular}{lrrrrrr} 
& \multicolumn{3}{c}{ Experimental } & \multicolumn{3}{c}{ Control } \\
Sutdy & Total & Mean & SD & Total & Mean & SD \\
1 & & & & & & \\
2 & 24 & 61 & 13 & 21 & 53 & 10 \\
3 & 41 & 59 & 14 & 40 & 52 & 12 \\
4 & 25 & 54 & 11 & 38 & 46 & 7 \\
5 & 24 & 63 & 14 & 27 & 50 & 10 \\
6 & 24 & 58 & 12 & 27 & 52 & 13 \\
7 & 48 & 62 & 21 & 50 & 50 & 10 \\
8 & 48 & 54 & 11 & 50 & 49 & 9 \\
9 & 10 & 55 & 9 & 10 & 48 & 11 \\
& 33 & 54 & 10 & 29 & 53 & 10
\end{tabular}

Random effects model 277

292

Heterogeneity: $\mathrm{I}^{2}=9 \%, t^{2}=0.0064, p=0.36$

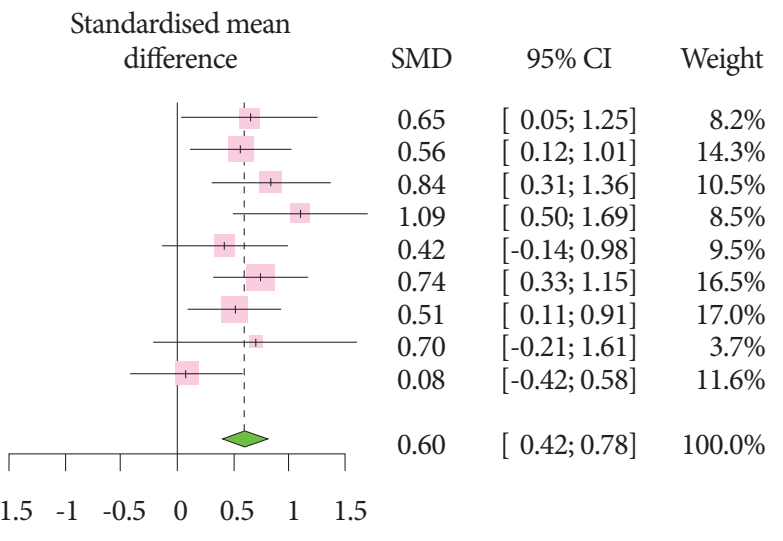

Inhibition

Sutdy

Experimental Control

Total Mean SD

Total Mean SD

Standardised mean

difference

SMD 95\% CI Weight

$\begin{array}{rrrrrr}24 & 59 & 13 & 21 & 50 & 9 \\ 41 & 58 & 15 & 40 & 50 & 9 \\ 25 & 56 & 13 & 38 & 47 & 8 \\ 24 & 56 & 13 & 27 & 50 & 9 \\ 48 & 54 & 11 & 50 & 46 & 6 \\ 10 & 59 & 15 & 10 & 46 & 7 \\ 33 & 55 & 10 & 29 & 53 & 11\end{array}$

Random effects model 205

215

Heterogeneity: $\mathrm{I}^{2}=15 \%, t^{2}=0.0131, p=0.31$

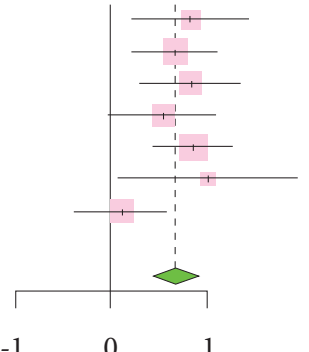

$0.84 \quad[0.23 ; 1.45] \quad 11.2 \%$

$0.68 \quad[0.23 ; 1.13] \quad 18.9 \%$

$0.85 \quad[0.32 ; 1.37] \quad 14.5 \%$

$0.55 \quad[-0.01 ; 1.11] \quad 13.1 \%$

$0.87 \quad[0.45 ; 1.28] \quad 21.4 \%$

$1.03 \quad[0.08 ; 1.97] \quad 5.0 \%$

$0.12 \quad[-0.38 ; 0.62] \quad 15.9 \%$

$0.67 \quad[0.45 ; 0.89] \quad 100.0 \%$

$\begin{array}{lll}-1 & 0 & 1\end{array}$

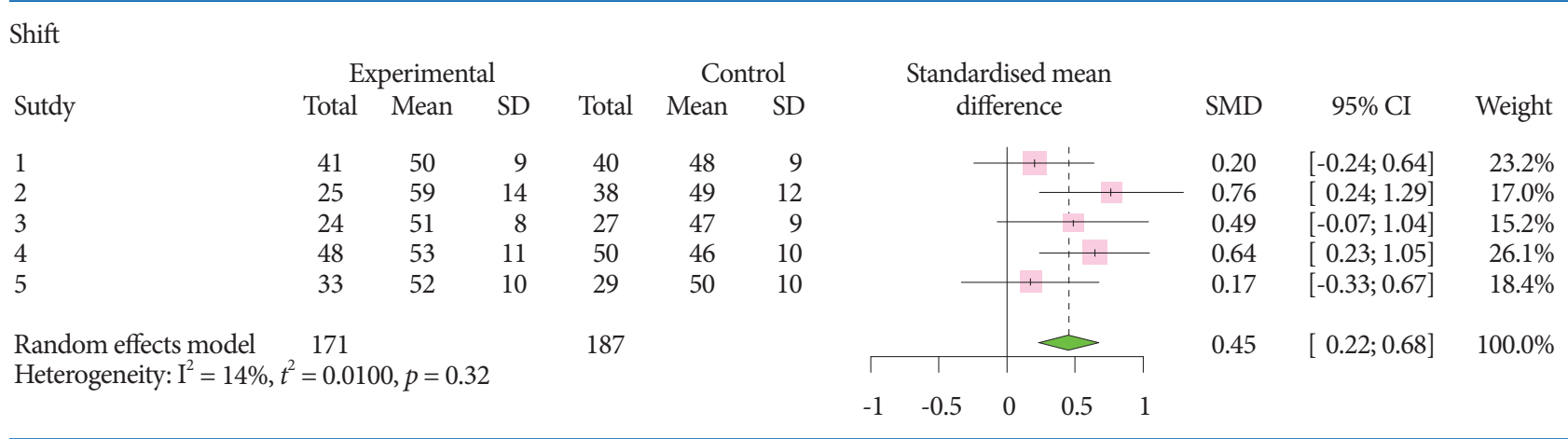


Appendix 2. Continued

Plan/organize

\begin{tabular}{lcccccr} 
& \multicolumn{3}{c}{ Experimental } & \multicolumn{3}{c}{ Control } \\
Sutdy & Total & Mean & SD & Total & Mean & SD \\
1 & 24 & 53 & 12 & 21 & 49 & 10 \\
2 & 25 & 53 & 11 & 38 & 46 & 8 \\
3 & 24 & 50 & 11 & 27 & 49 & 11 \\
4 & 48 & 52 & 11 & 50 & 49 & 9 \\
5 & 33 & 52 & 8 & 29 & 54 & 9
\end{tabular}

Random effects model 154

165

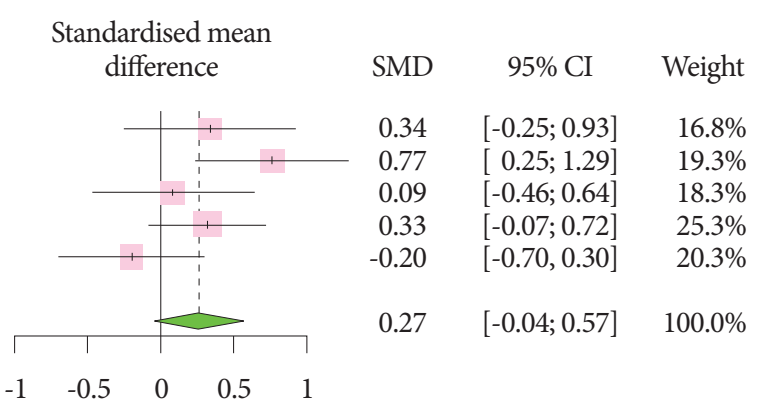

Emotion control

\begin{tabular}{lcccccr} 
& \multicolumn{3}{c}{ Experimental } & \multicolumn{3}{c}{ Control } \\
Sutdy & Total & Mean & SD & Total & Mean & SD \\
1 & 25 & 56 & 14 & 38 & 48 & 11 \\
2 & 48 & 52 & 12 & 50 & 46 & 9 \\
3 & 33 & 52 & 11 & 29 & 51 & 12
\end{tabular}

Random effects model 106

117 12

Heterogeneity: $\mathrm{I}^{2}=5 \%, t^{2}=0.0029, p=0.35$

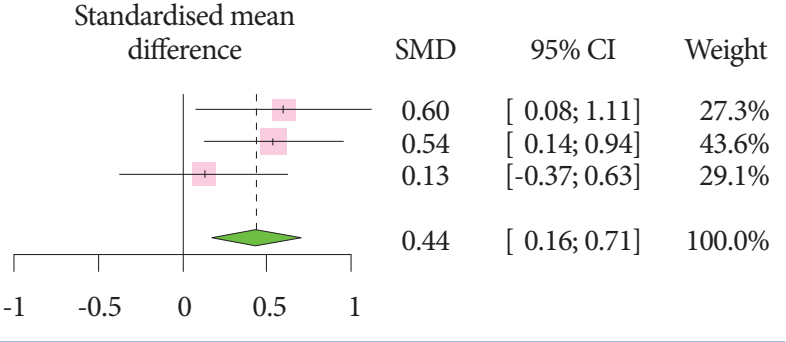

Sustained sequential processing

\begin{tabular}{lcccccc} 
& \multicolumn{3}{c}{ Experimental } & \multicolumn{3}{c}{ Control } \\
Sutdy & Total & Mean & SD & Total & Mean & SD \\
1 & 24 & 60 & 16 & 27 & 50 & 10 \\
2 & 48 & 59 & 15 & 50 & 50 & 10 \\
& & & & & & \\
Random effects model & 72 & & & 77 & & \\
Heterogeneity: $\mathrm{I}^{2}=0 \%, t^{2}=0, p=0.97$ & & &
\end{tabular}

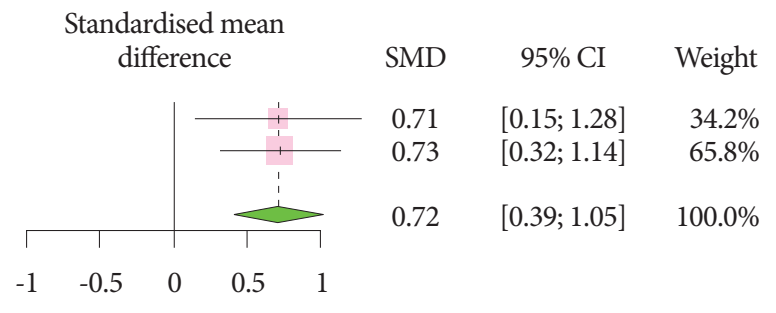

Attention

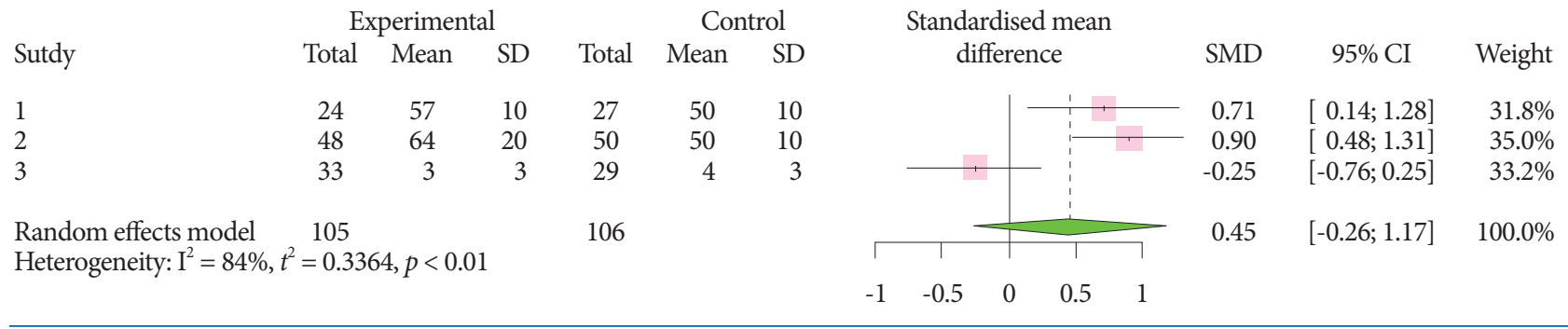

Visual-spatial organization

\begin{tabular}{lrrrrrr} 
& \multicolumn{3}{c}{ Experimental } & & \multicolumn{2}{c}{ Control } \\
Sutdy & Total & Mean & SD & Total & Mean & SD \\
1 & 24 & 54 & 14 & 27 & 50 & 10 \\
2 & 48 & 51 & 9 & 50 & 50 & 10 \\
& & & & & & \\
Random effects model & 72 & & & 77 & & \\
Heterogeneity: $\mathrm{I}^{2}=0 \%, t^{2}=0, p=0.57$ & & &
\end{tabular}

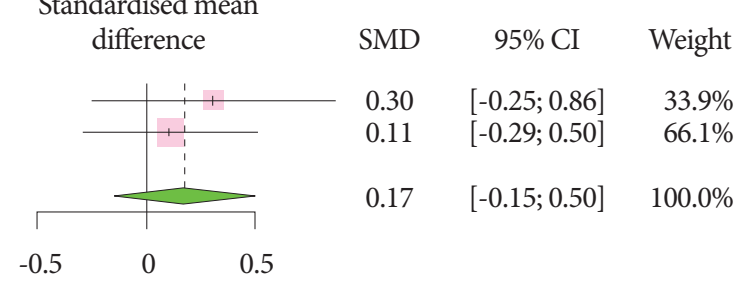

SD: standard deviation, SMD: standardised mean difference, CI: confidence interval 